\title{
Effects of blood pressure lowering and intensive glucose control on the incidence and progression of retinopathy in patients with type 2 diabetes mellitus: a randomised controlled trial
}

\author{
J. W. J. Beulens • A. Patel • J. R. Vingerling • \\ J. K. Cruickshank • A. D. Hughes • A. Stanton • J. Lu • \\ S. A. McG Thom • D. E. Grobbee • R. P. Stolk • \\ on behalf of the AdRem project team and ADVANCE \\ management committee
}

Received: 13 February 2009 / Accepted: 22 June 2009 /Published online: 25 July 2009

(C) Springer-Verlag 2009

\begin{abstract}
Aims/hypothesis The aim of the present study was to investigate the effect of blood pressure lowering and intensive glucose control on the incidence and progression of retinopathy in type 2 diabetic patients.

Methods The Action in Diabetes and Vascular Disease: Preterax and Diamicron MR Controlled Evaluation (ADVANCE) Retinal Measurements study, a substudy of ADVANCE, is a randomised (using a central, computerbased procedure) controlled $2 \times 2$ factorial trial comprising a double-blind comparison of blood pressure lowering with perindopril-indapamide vs placebo, and an open comparison of standard vs intensive glucose control targeting a
\end{abstract}

*A list of members of the AdRem study staff, the ADVANCE Management Committee and Participating AdRem centres can be found in the Electronic supplementary material.

Electronic supplementary material The online version of this article (doi:10.1007/s00125-009-1457-x) contains supplementary material, which is available to authorised users.

J. W. J. Beulens $(\bowtie) \cdot$ D. E. Grobbee $\cdot$ R. P. Stolk Julius Center for Health Sciences and Primary Care, University Medical Center Utrecht,

PO Box 85500, 3508 GA Utrecht, the Netherlands

e-mail: J.Beulens@umcutrecht.nl

A. Patel

The George Institute for International Health,

University of Sydney,

Sydney, NSW, Australia

J. R. Vingerling

Department of Ophthalmology, Erasmus Medical Center,

Rotterdam, the Netherlands
$\mathrm{HbA}_{1 \mathrm{c}}$ of $\leq 6.5 \%$ in 1,602 diabetic patients from ADVANCE centres with access to retinal cameras conducted from 2001 to 2008. At baseline and the final visit, seven-field stereoscopic retinal photographs were taken and graded by blinded readers (gradeable baseline and final photographs from 1,241 patients). Progression of $\geq 2$ steps in the Early Treatment of Diabetic Retinopathy Study classification (using the eye with worst grading) was the primary outcome.

Results Retinopathy progressed in 59 (4.8\%) patients and developed in $128(10.3 \%)$ patients over 4.1 years. Fewer patients on blood pressure-lowering treatment $(n=623)$ experienced incidence or progression of retinopathy com-

J. R. Vingerling

Epidemiology and Biostatistics, Erasmus Medical Center, Rotterdam, the Netherlands

\section{J. K. Cruickshank}

Cardiovascular Sciences Research Group,

University of Manchester and Royal Infirmary,

Manchester, UK

\section{A. D. Hughes $\cdot$ S. A. McG Thom}

International Centre for Circulatory Health,

National Heart and Lung Institute, Imperial College London,

London, UK 
pared with patients on placebo $(n=618)$, but the difference was not significant (OR 0.78; 95\% CI 0.57-1.06; $p=0.12$ ). Blood pressure-lowering treatment reduced the occurrence of macular oedema (OR $0.50 ; 95 \%$ CI $0.29-0.88 ; p=0.016$ ) and arteriovenous nicking compared with placebo (OR $0.60 ; 95 \%$ CI $0.38-0.94 ; p=0.025)$. Compared with standard glucose control $(n=611)$, intensive glucose control $(n=630)$ did not reduce $(p=0.27)$ the incidence and progression of retinopathy (OR $0.84 ; 95 \%$ CI $0.61-1.15$ ). Lower, borderline significant risks of microaneurysms, hard exudates and macular oedema were observed with intensive glucose control, adjusted for baseline retinal haemorrhages. These effects of the two treatments were independent and additive. Adverse events in the ADVANCE study are reported elsewhere.

Conclusions/interpretation Blood pressure lowering or intensive glucose control did not significantly reduce the incidence and progression of retinopathy, although consistent trends towards a benefit were observed, with significant reductions in some lesions observed with both interventions.

Trial registration: ClinicalTrials.gov ID no. NCT00145925. Funding: Grants from Servier and the National Health and Medical Research Council of Australia

Keywords Blood pressure lowering - Diabetic retinopathy Intensive glucose control

$\begin{array}{ll}\begin{array}{l}\text { Abbreviations } \\ \text { AdRem }\end{array} & \text { ADVANCE Retinal Measurements } \\ \text { ADVANCE } & \text { Action in Diabetes and Vascular Disease: } \\ & \text { Preterax and Diamicron MR Controlled } \\ & \text { Evaluation } \\ \text { EMEA } & \text { European Medicines Agency } \\ \text { ETDRS } & \text { Early Treatment of Diabetic Retinopathy } \\ & \text { Study }\end{array}$

A. Stanton

Molecular and Cellular Therapeutics and RCSI Research Institute, Royal College of Surgeons in Ireland,

Dublin, Ireland

J. $\mathrm{Lu}$

Department of Endocrinology, Chinese PLA General Hospital, Beijing, China

R. P. Stolk

Department of Epidemiology,

University Medical Center Groningen, University of Groningen, Groningen, the Netherlands $\begin{array}{ll}\text { HOPE } & \text { Heart Outcomes Prevention Evaluation } \\ \text { UKPDS } & \text { UK Prospective Diabetes Study }\end{array}$

\section{Introduction}

By 2030, an estimated 350 million people will have type 2 diabetes worldwide [1]. Diabetic retinopathy is a progressive disorder of the retinal microcirculation and is the most common cause of blindness among people aged 30-69 years [2, 3].

Both blood pressure and blood glucose are continuously associated with a risk of diabetic retinopathy [4-7]. The UK Prospective Diabetes Study (UKPDS) is the only intervention study to date of sufficient size to study the effect of glucose and blood pressure lowering on retinopathy in diabetic patients. It showed that improved glucose control reduced the risk of microvascular disease by $25 \%$ [8]. However, that effect was found only after the start of an additional antihypertensive trial, 10 years after the glycaemic arm began [8]. Among the 1,148 hypertensive UKPDS patients, tight blood pressure control reduced the incidence and progression of retinopathy by $34 \%$ after 7.5 years $[9,10]$.

The UKPDS was restricted to newly diagnosed patients predominantly of European origin and the blood pressurelowering arm was restricted to hypertensive patients. Blood pressure-lowering agents can be used irrespective of initial blood pressure level or the use of other antihypertensive medications. This would produce a smaller average blood pressure reduction than that seen in the UKPDS, but would shift the blood pressure distribution of the entire population downwards. The Action in Diabetes and Vascular Disease: Preterax and Diamicron MR Controlled Evaluation (ADVANCE) study showed that this strategy reduced cardiovascular death and coronary and renal events [11]. Finally, the mean $\mathrm{HbA}_{1 \mathrm{c}}$ in the intensive glucose control intervention group in UKPDS was only maintained below $7 \%$ for the first 5 years of the study. Current guidelines include targets as low as $6.5 \%$ in Europe and $7.0 \%$ in the USA $[12,13]$.

In the entire ADVANCE study, there was no risk reduction of laser photocoagulation by blood pressure lowering [11] or by intensive glucose control [14]. Here we report the results of the ADVANCE Retinal Measurements (AdRem) study, a substudy of ADVANCE, to investigate effects on the incidence and progression of retinopathy.

\section{Methods}

AdRem was performed in 39 centres in 14 countries in Asia, Australia, Europe and North America. Approval for 
the trial was obtained from the institutional review board of each centre and all participants provided written informed consent. The study design and the methods used in AdRem are published in detail elsewhere [15] and briefly described here. The study is registered with Clinicaltrials.gov, no. NCT00145925.

Design ADVANCE was a $2 \times 2$ factorial, randomised controlled trial in 11,140 type 2 diabetic patients receiving standard care, as described elsewhere [16]. The primary endpoints were composite measures of macro- and microvascular disorders. After a 6 week run-in period on a fixed combination tablet consisting of perindopril $(2 \mathrm{mg})$ and indapamide $(0.625 \mathrm{mg})$ and usual glucose-lowering treatment, eligible participants were randomly assigned in a $2 \times 2$ factorial design to one of four treatment combinations. The two main effects comparisons were a double-blind comparison of blood pressure-lowering vs placebo, and an open comparison of gliclazide MR-based intensive glucoselowering regimen targeting an $\mathrm{HbA}_{1 \mathrm{c}}$ of $6.5 \%$ or less vs standard guideline-based glucose lowering using a prospective, randomised, open-label, blinded endpoint evaluation design.

Setting and participants The ADVANCE study randomised type 2 diabetic patients, diagnosed at the age of 30 years or older and aged 55 years or older at study entry. Potentially eligible patients were also required to have at least one additional risk factor for cardiovascular disease [11, 16]. AdRem was conducted in study centres with access to retinal cameras. In addition to the inclusion and exclusion criteria of ADVANCE, patients were excluded from AdRem if they had had a previous ophthalmological intervention procedure (such as laser coagulation treatment or vitrectomy) or if it was unlikely that good quality stereo photographs could be taken, because of severe cataract or pupils that did not dilate to at least $4 \mathrm{~mm}$.

Randomisation and interventions The blood pressurelowering treatment was a fixed low-dose combination of perindopril (2 $\mathrm{mg}$ doubled to $4 \mathrm{mg}$ after 3 months) and indapamide ( $0.625 \mathrm{mg}$ doubled to $1.25 \mathrm{mg}$ after 3 months). For intensive glucose control, other oral glucose-lowering agents and insulin were added to a long-acting sulfonylurea (gliclazide MR $30 \mathrm{mg}$ uptitrating to $120 \mathrm{mg}$ as required), over time at the discretion of the treating physician, to achieve a target $\mathrm{HbA}_{1 \mathrm{c}}$ of $6.5 \%$ or less. Study treatments were randomly allocated using a central, computer-based procedure, stratified by study centre, history of macro- or microvascular disease and background use of perindopril at baseline. The use of other concomitant treatments during follow-up remained at the discretion of the treating physician with some exceptions: the use of thiazide or thiazide-like diuretics was not allowed, and open-label perindopril, to a maximum of $4 \mathrm{mg}$ a day, was the only ACE inhibitor allowed, ensuring a maximum dose of $8 \mathrm{mg}$ perindopril; gliclazide MR was the only sulfonylurea allowed in the intensive glucose control group; and sulfonylureas except gliclazide were allowed in the standard glucose control group.

Photography Retinal photographs were taken after the ADVANCE randomisation visit and at the final visit of the blood pressure arm of the trial (completed 6 months before the glucose arm) with a median interval of 2 months (IQR 1-6 months). For those patients with photographs taken within 3 months after the randomisation visit, another photograph was taken at the visit 2 years after randomisation. Seven standard field stereoscopic photographs of the left and right eyes were taken with $35 \mathrm{~mm}$ high-quality colour films (Kodak EPR64 135-36), according to the Early Treatment of Diabetic Retinopathy Study (ETDRS) protocol [17]. The seven fields included one centred on the optic disc, one centred on the macula, one temporal to the macula, and two superior and two inferior fields. In patients with non-gradeable images according to strict criteria [15], repeat photographs were sought.

Retinopathy grading The ETDRS classification was slightly modified in the UKPDS, and this modified classification was used in the AdRem study [7]. Detected lesions were graded in comparison with the ETDRS final scale standard photographs. Retinal vascular lesions were also assessed in each field using standard photographs [15]. All images were graded centrally (at the University Medical Center Utrecht) by two independent readers trained by the Retinopathy Grading Center, Hammersmith Hospital, Imperial College London. Approximately $15 \%$ of the photographs were judged ungradeable throughout the study. If there were discordant readings between the two readers, this was solved in consensus in a meeting with both readers and an experienced ophthalmologist. In $8.8 \%$ of the gradeable photographs there was a discordant reading, resulting in a kappa of 0.82 .

Substudy outcomes The primary endpoint of the study was progression of $\geq 2$ steps in ETDRS classification with laser coagulation therapy during follow-up as the final step in ETDRS classification, including both incidence and progression of retinopathy. Secondary endpoints included $\geq 1$ or $\geq 3$ steps of progression in ETDRS classification, incidence as a change of $\geq 2$ steps and progression as a change of $\geq 3$ steps in ETDRS classification according to the European Medicines Agency (EMEA) guideline, laser coagulation therapy, each of the separate retinal vascular lesions (arteriovenous nicking, microaneurysms, retinal 
haemorrhages, cotton wool spots, hard exudates, macular oedema), and any vascular lesion. Macular oedema was defined as definite macular thickening within 1 disc diameter from the centre of the macula, assessed in field 2 by stereoscopic viewing. This was the only outcome in the study defined post hoc [7]. The score in the worst eye at each assessment was used to calculate incidence and progression. The presence of retinopathy at baseline was defined as ETDRS $\geq 20$.

Statistical analysis AdRem was designed to include 2,000 participants, which would have provided at least $85 \%$ power with a two-tailed type I error of 5\% to detect an absolute reduction of $6 \%$ in the event rate of the primary endpoint associated with both blood pressure lowering and intensive glucose control. This assumed an event rate of $27.8 \%$ over 6 years of follow-up based on data from UKPDS.

All analyses were based on the intention-to-treat principle (1,241 patients with gradeable baseline and final photographs). In the absence of a final retinal photograph, available 2 year photographs were used. Treatment effects in both arms for all endpoints were estimated using logistic regression, adjusted for centre and randomisation of the other treatment arm. When differences in baseline characteristics were observed, adjustment for those characteristics was conducted as a secondary analysis. Differences in blood pressure and changes in weighted $\mathrm{HbA}_{1 \mathrm{c}}$ during the study between treatment groups were analysed by analysis of variance using a mixed model. The homogeneity of treatment effects for several prespecified factors (the other treatment arm, presence of retinopathy at baseline) was estimated by including interaction terms in the logistic model. All analyses were performed using SAS version 9.1 (SAS Institute, Cary, NC, USA).

\section{Results}

The trial profile showed that 2,130 of the 2,863 eligible patients consented to participate (Fig. 1). After further exclusions (shown in Fig. 1), the study population comprised 1,602 patients. During follow-up, 324 photographs were not received and 37 photographs were not gradeable, loss of follow-up data being similar across treatment arms. Finally, 1,241 patients with gradeable baseline and final photographs were included in the intention-to-treat analysis.

There were no clinically meaningful differences in baseline characteristics between treatment groups in either study arm (Table 1). At baseline, mean age was $65.6 \pm$ 5.8 years, median duration of diabetes 6 years (2-11 years),
$61.3 \%$ of the population was male and retinopathy (ETDRS $\geq 20$ ) was present among $40.1 \%$ of patients. Systolic and diastolic blood pressures (mean \pm SD) were $142.7 \pm 21.7$ and $79.3 \pm 10.8 \mathrm{mmHg}$, and $\mathrm{HbA}_{1 \mathrm{c}}$ was $7.4 \pm 1.5 \%$. Baseline characteristics were well balanced across treatment groups in both study arms among patients with valid photographs at baseline and during follow-up, although the presence of retinal haemorrhages was slightly higher among those on intensive glucose-lowering therapy $(50.3 \%)$ than on standard therapy $(43.9 \%)$. The study population did not differ substantially compared with the entire ADVANCE population, except for a slightly shorter duration of diabetes.

Compared with placebo, active blood pressure-lowering therapy gave a mean reduction in systolic blood pressure of $6.1 \pm 1.2 \mathrm{mmHg}$ and diastolic blood pressure of $2.3 \pm$ $0.6 \mathrm{mmHg}(p<0.001$ for both; Fig. 2a). Intensive glucose control significantly reduced $\mathrm{HbA}_{1 \mathrm{c}}$ from $7.4 \%$ to $6.5 \%$, whereas $\mathrm{HbA}_{1 \mathrm{c}}$ remained unchanged with standard glucose control ( $p<0.001$; Fig. 2b). Use of insulin during follow-up was more frequent among those randomised to intensive glucose control (38.8\%) compared with patients assigned standard $(20.8 \%)$ glucose control $(p<0.001)$.

We documented progression of retinopathy in $59(4.8 \%)$ patients and incident retinopathy in $128(10.3 \%)$ patients during a median follow-up of 4.1 years. Fewer patients on blood pressure-lowering therapy experienced new or worsening retinopathy compared with those on placebo (OR 0.78; 95\% CI 0.57-1.06; $p=0.12$ ), but the difference was not significant (Table 2). The absolute risk of incidence and progression was $16.7 \%$ for placebo and $13.5 \%$ for perindopril-indapamide treatment (risk difference, 3.2\%). Similar results were observed for progression of $\geq 3$ steps in the ETDRS classification and the endpoint definition according to EMEA, while progression of $\geq 1$ steps in the ETDRS classification was not different between treatments. The presence of any retinal vascular lesion was similar for blood pressure-lowering and placebo $(p=0.34)$, but active therapy significantly reduced the presence of macular oedema (OR 0.50; 95\% CI 0.29-0.88; $p=0.016$ ) and arteriovenous nicking (OR $0.60 ; 95 \%$ CI $0.38-0.94$; $p=0.025)$ compared with placebo. These results were largely unchanged when adjusted for the presence of baseline retinal haemorrhages and were independent of baseline systolic and diastolic blood pressure (OR 0.77; 95\% CI $0.57-1.06$ for $\geq 2$ steps of progression). Regression of retinopathy ( $\geq 2$ steps in the ETDRS classification) was not significantly different between blood pressure-lowering and placebo treatment.

Intensive glucose-lowering treatment did not significantly reduce the incidence and progression of retinopathy (OR $0.84 ; 95 \%$ CI $0.61-1.15 ; p=0.27$; Table 2). The absolute risk of incidence and progression was $16.2 \%$ for standard 


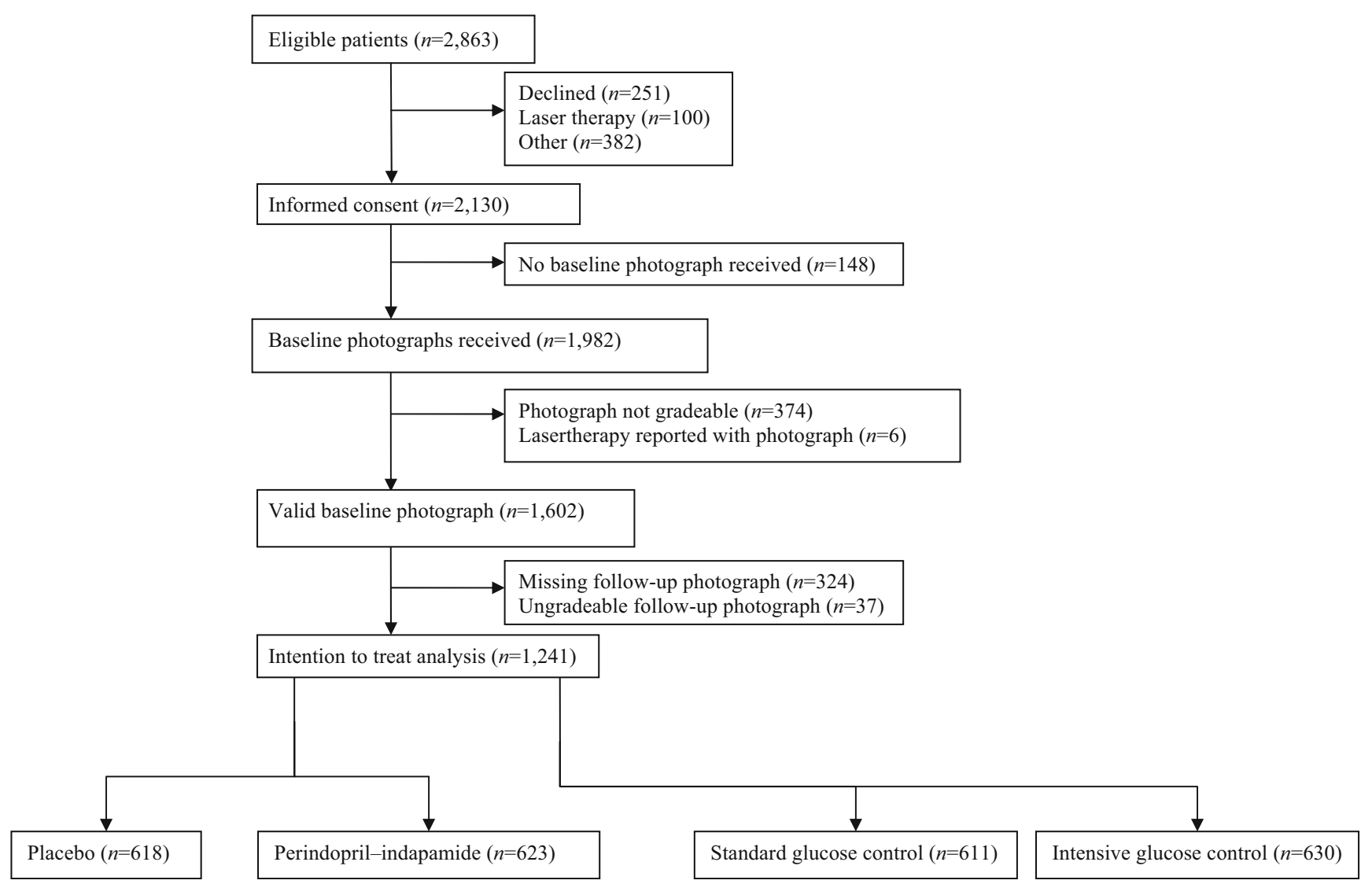

Fig. 1 Flowchart of patients in the AdRem study

glucose control and $14.0 \%$ for intensive glucose control (risk difference, 2.2\%). Similar results were observed for the incidence and progression of $\geq 1$ steps, $\geq 3$ steps and the endpoint definition according to EMEA (Table 2). Similarly, the presence of any retinal vascular lesion did not differ between intensive glucose-lowering and usual treatment (OR $0.97 ; 95 \%$ CI $0.78-1.12 ; p=0.81$ ), nor did any of the other specified retinal vascular lesions differ. However, after adjusting for the presence of retinal haemorrhages at baseline, lower, albeit borderline significant, risks of arteriovenous nicking, microaneurysms, retinal haemorrhages, hard exudates and macular oedema were observed in the intensive glucoselowering arm. These results were independent of baseline $\mathrm{HbA}_{1 \mathrm{c}}$ concentration. Regression of retinopathy ( $\geq 2$ steps in ETDRS classification) was not significantly different between intensive and standard glucose control treatments. Similar results were observed among patients with a reduction of $\mathrm{HbA}_{1 \mathrm{c}}>0.5 \%$ in 6 months (OR $0.95 ; 95 \%$ CI $0.56-1.61$ ), although it should be noted that subgroup analyses based on post-randomisation characteristics are potentially biased.

The effects of blood pressure lowering and intensive glucose control were independent and additive, since no significant interactions between the treatment arms were observed. For example, the odds ratio for progression of $\geq 2$ steps in ETDRS classification for perindopril-indapamide and intensive glucose control against placebo and standard glucose control was 0.66 (95\% CI $0.43-1.02)$. The corresponding odds ratio for macular oedema was 0.34 (95\% CI 0.15-0.77) and that for arteriovenous nicking was 0.42 (95\% CI 0.22-0.82).

Among patients without baseline retinopathy, odds ratios for progression of $\geq 2$ steps in retinopathy were slightly lower for both blood pressure-lowering treatments (OR $0.74 ; 95 \%$ CI $0.50-1.08$ ) and intensive glucose control (OR $0.75 ; 95 \%$ CI $0.49-1.07$ ), although interaction terms did not reach significance for any of the endpoints. Using higher cut-off values to define presence of the specific vascular lesions gave similar results. Only for arteriovenous nicking were numbers of events too low using a higher cut-off value to provide reliable data (data not shown).

\section{Discussion}

Both blood pressure lowering and intensive glucose control produced consistent trends to benefits in patients with type 2 diabetes. These trends were independent of initial blood pressures for the blood pressure lowering comparison and 
Table 1 Baseline characteristics of 1,602 type 2 diabetic patients in the AdRem study according to blood pressure-lowering treatment (perindopril-indapamide) vs placebo and standard vs intensive blood glucose-lowering treatment

\begin{tabular}{|c|c|c|c|c|}
\hline Characteristic & Placebo & $\begin{array}{l}\text { Perindopril-- } \\
\text { indapamide }\end{array}$ & $\begin{array}{l}\text { Standard glucose- } \\
\text { lowering therapy }\end{array}$ & $\begin{array}{l}\text { Intensive glucose- } \\
\text { lowering therapy }\end{array}$ \\
\hline$n$ & 796 & 806 & 811 & 791 \\
\hline Age (years) & $65.6 \pm 5.9$ & $65.6 \pm 5.8$ & $65.6 \pm 5.7$ & $65.6 \pm 6.0$ \\
\hline Time of follow-up (years); median (IQR) & $4.1(3.7-4.3)$ & $4.1(3.7-4.3)$ & $4.1(3.7-4.3)$ & $4.1(3.7-4.3)$ \\
\hline Sex (\% female) & 37.1 & 40.3 & 39.3 & 38.1 \\
\hline \multicolumn{5}{|l|}{ Ethnicity (\%) } \\
\hline White & 48.5 & 47.0 & 48.2 & 47.3 \\
\hline Chinese & 37.9 & 38.3 & 36.7 & 39.6 \\
\hline South Asian & 8.5 & 9.6 & 9.6 & 8.5 \\
\hline Duration of diabetes (years); median (IQR) & $6(2-11)$ & $6(2-11)$ & $6(2-11)$ & $6(2,11)$ \\
\hline \multicolumn{5}{|l|}{ ETDRS classification level } \\
\hline 10: diabetic retinopathy absent $(\%)$ & 50.6 & 50.4 & 51.3 & 49.7 \\
\hline 14: diabetic retinopathy questionable $(\%)$ & 8.5 & 10.3 & 8.6 & 10.2 \\
\hline 20: microaneurysms only (\%) & 22.4 & 21.8 & 22.0 & 22.3 \\
\hline 35: mild non-proliferative diabetic retinopathy (\%) & 8.4 & 8.3 & 7.8 & 9.0 \\
\hline 43: moderate non-proliferative diabetic retinopathy (\%) & 6.9 & 5.0 & 6.0 & 5.8 \\
\hline 47: moderate or severe non-proliferative diabetic retinopathy $(\%)$ & 1.8 & 1.6 & 1.6 & 1.8 \\
\hline 53: severe non-proliferative diabetic retinopathy (\%) & 0.9 & 1.1 & 1.5 & 0.5 \\
\hline 61-81: proliferative diabetic retinopathy (\%) & 0.5 & 1.5 & 1.2 & 0.8 \\
\hline \multicolumn{5}{|l|}{ ARIC classification } \\
\hline Arteriovenous crossing changes (nicking) (\%) & 11.1 & 8.6 & 9.3 & 10.4 \\
\hline Microaneurysms (\%) & 27.0 & 26.3 & 27.0 & 26.3 \\
\hline Retinal haemorrhages (\%) & 46.7 & 44.4 & 43.7 & 47.5 \\
\hline Cotton wool spots (soft exudates) (\%) & 27.3 & 25.0 & 25.8 & 26.4 \\
\hline Hard exudates $(\%)$ & 15.1 & 17.6 & 15.8 & 16.9 \\
\hline Retinopathy (ETDRS $\geq 20$ ) (\%) & 40.9 & 39.3 & 40.1 & 40.1 \\
\hline BMI $\left(\mathrm{kg} / \mathrm{m}^{2}\right)$ & $27.7 \pm 4.7$ & $27.7 \pm 4.9$ & $27.6 \pm 4.8$ & $27.8 \pm 4.8$ \\
\hline $\mathrm{HbA}_{1 \mathrm{c}}(\%)$ & $7.3 \pm 1.4$ & $7.5 \pm 1.5$ & $7.4 \pm 1.5$ & $7.4 \pm 1.5$ \\
\hline Glucose $(\mathrm{mmol} / \mathrm{l})$ & $8.5 \pm 2.8$ & $8.5 \pm 2.8$ & $8.4 \pm 2.7$ & $8.6 \pm 2.9$ \\
\hline Systolic blood pressure (mmHg) & $143.1 \pm 21.4$ & $142.3 \pm 22.0$ & $142.7 \pm 21.2$ & $142.7 \pm 22.2$ \\
\hline Diastolic blood pressure (mmHg) & $79.5 \pm 10.5$ & $79.2 \pm 11.2$ & $79.0 \pm 10.8$ & $79.6 \pm 10.9$ \\
\hline Use of blood pressure-lowering agents (\%) & 69.1 & 70.4 & 71.0 & 68.4 \\
\hline History of hypertension (\%) & 64.2 & 65.3 & 65.1 & 64.4 \\
\hline Combined systolic and diastolic BP elevation (\%) & 53.5 & 53.0 & 53.6 & 52.8 \\
\hline Smoking (\% yes) & 15.6 & 13.2 & 14.3 & 14.4 \\
\hline Use of oral hypoglycaemic agents (\%) & 87.9 & 88.5 & 88.3 & 88.1 \\
\hline Use of insulin (\%) & 1.1 & 0.7 & 1.0 & 0.9 \\
\hline
\end{tabular}

Data are mean \pm SD unless otherwise indicated

ARIC, Atherosclerosis Risk in Communities [27]

of $\mathrm{HbA}_{1 \mathrm{c}}$ for the glucose control comparison. The reductions observed were not statistically significant for either of the interventions, although the incidence of some retinal vascular lesions (for example, macular oedema) was reduced in both arms of the trial.

Strengths of this study include its design and retinal photography using seven-field stereoscopic retinal photog- raphy of both eyes. The main limitation of this study is the lower than planned sample size. Gradeable baseline and follow-up photographs were intended to be obtained for 2,000 patients in AdRem [15]. Despite intensive efforts to collect both baseline and follow-up photographs for all patients, 37 photographs were ungradeable and 324 photographs were not received, leaving only 1,241 patients for 
Fig. 2 Mean changes in (a) systolic and diastolic blood pressure during the study according to blood pressurelowering treatment and (b) mean $\mathrm{HbA}_{1 \mathrm{c}}$ according to blood glucose-lowering treatment among 1,241 type 2 diabetic patients in the AdRem study. a squares, placebo; triangles, perindopril-indapamide; difference in systolic blood pressure (black squares/triangles): $6.1 \pm$ $1.2 \mathrm{mmHg}(p<0.001)$; difference in diastolic blood pressure (white squares/triangles): $2.3 \pm$ $0.6 \mathrm{mmHg}(p<0.001)$.

b squares, standard glucose control; triangles, intensive glucose control; difference in mean $\mathrm{HbA}_{1 \mathrm{c}}, 0.7 \pm 0.1 \%$; $p<0.001$. R, randomisation a

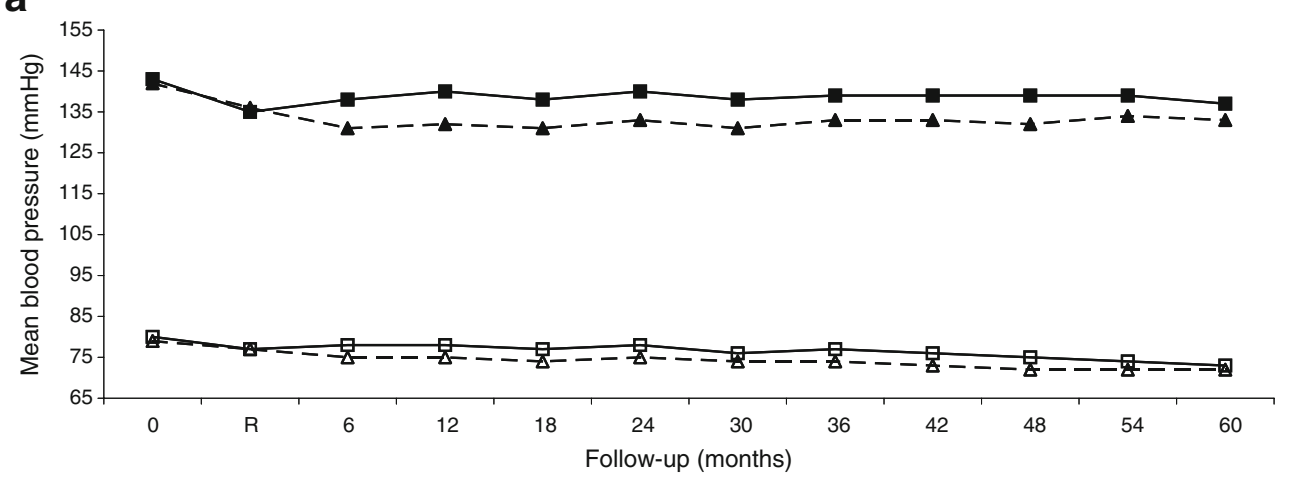

b

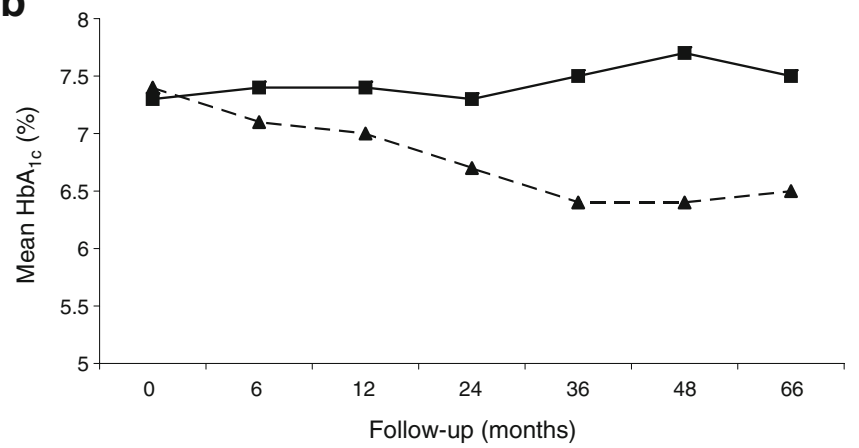

the primary analysis. In addition, our sample size calculations assumed an event rate of $27.8 \%$ in the standard glucose-lowering treatment groups, which ultimately proved to be only $12.2 \%$. This was probably attributable to improved diabetes care since UKPDS, as reflected by the higher background level of medication use in our study population compared with the UKPDS population $[8,11,14]$.

A second limitation of this study is the quality assurance of the photographs. Although we recorded disagreement between the readers throughout the study, resulting in a kappa value of 0.85 , a formal quality assurance of intrareader agreement was not performed. This may have led to random error in our data, particularly for results on the occurrence of individual lesions. We used progression of $\geq 2$ steps in ETDRS classification as the primary endpoint, because one step of progression may still reflect measurement error in these measures. Indeed, our results showed stronger associations when using $\geq 2$ steps of progression, which was confirmed by a secondary analysis with $\geq 3$ steps of progression. Nevertheless, such random error may still be present in our results and should be accounted for when interpreting these data. However, assuming that the observed relation is true, such random error can only have attenuated the association.

The incidence and progression of retinopathy (as assessed by $\geq 2$ steps of progression in ETDRS classification) tended to be lower after blood pressure-lowering treatment compared with placebo after 4.1 years (OR 0.78; 95\% CI $0.57-1.07$ ). This risk reduction is similar to the non-significant reduction of $25 \%$ in deterioration of $\geq 2$ steps on the ETDRS scale reported by UKPDS after 4.5 years of follow-up (OR $0.75 ; 0.55-1.02)$ [10]. The risk reduction in UKPDS increased to $34 \%$ after 7.5 years of follow-up. It should be noted that the blood pressure intervention in UKPDS was performed among a subgroup of patients with diabetes and hypertension, whereas we included patients irrespective of initial blood pressure level. The initial blood pressures and mean blood pressure reduction observed in AdRem are therefore much smaller than those observed in the UKPDS [10]. However, after 4 years of follow-up similar results were observed; significance was reached only after 7.5 years of follow-up in the UKPDS. More recently, the DIabetic REtinopathy Candesartan Trials (DIRECT-Protect 2) reported a nonsignificant $13 \%$ relative reduction in retinopathy with candesartan treatment compared with placebo among type 2 diabetic patients and background retinopathy, but regression of retinopathy occurred more often with candesartan treatment [18]. These results differ from ours, because we could not detect any effects on the regression of retinopathy and progression seemed to be particularly reduced among those without baseline retinopathy.

Macular oedema, which is the most common cause of loss of vision in diabetic patients, was significantly reduced after blood pressure-lowering treatment. Arteriovenous 
Table 2 Odds ratios $(95 \%$ CI) of incidence and progression of retinopathy for perindopril-indapamide treatment vs placebo and intensive vs standard blood glucose-lowering treatment

\begin{tabular}{|c|c|c|c|c|c|c|}
\hline Variable & Placebo & $\begin{array}{l}\text { Perindopril- } \\
\text { indapamide }\end{array}$ & $p$ value & $\begin{array}{l}\text { Standard glucose- } \\
\text { lowering treatment }\end{array}$ & $\begin{array}{l}\text { Intensive glucose- } \\
\text { lowering treatment }\end{array}$ & $p$ value \\
\hline \multicolumn{7}{|c|}{ Progression of $\geq 2$ steps in ETDRS classification } \\
\hline Cases & 103 & 84 & & 99 & 88 & \\
\hline OR $(95 \% \mathrm{CI})$ & 1.0 & $0.78(0.57-1.06)$ & 0.12 & 1.0 & $0.84(0.61-1.15)$ & 0.27 \\
\hline Adjusted $\mathrm{OR}^{\mathrm{a}}(95 \% \mathrm{CI})$ & 1.0 & $0.78(0.57-1.06)$ & 0.11 & 1.0 & $0.85(0.62-1.16)$ & 0.30 \\
\hline \multicolumn{7}{|c|}{ Progression of $\geq 1$ steps in ETDRS classification } \\
\hline Cases & 135 & 132 & & 137 & 130 & \\
\hline OR $(95 \% \mathrm{CI})$ & 1.0 & $0.96(0.73-1.26)$ & 0.77 & 1.0 & $0.90(0.69-1.18)$ & 0.44 \\
\hline Adjusted $\mathrm{OR}^{\mathrm{a}}(95 \% \mathrm{CI})$ & 1.0 & $0.96(0.73-1.26)$ & 0.76 & 1.0 & $0.90(0.69-1.18)$ & 0.45 \\
\hline \multicolumn{7}{|c|}{ Progression of $\geq 3$ steps in ETDRS classification, incidence of $\geq 2$ steps (EMEA) } \\
\hline Cases & 92 & 75 & & 90 & 77 & \\
\hline OR $(95 \% \mathrm{CI})$ & 1.0 & $0.78(0.56-1.09)$ & 0.14 & 1.0 & $0.81(0.58-1.12)$ & 0.20 \\
\hline Adjusted $\mathrm{OR}^{\mathrm{a}}(95 \% \mathrm{CI})$ & 1.0 & $0.78(0.56-1.08)$ & 0.13 & 1.0 & $0.83(0.60-1.15)$ & 0.26 \\
\hline \multicolumn{7}{|c|}{ Progression of $\geq 3$ steps in ETDRS classification } \\
\hline Cases & 41 & 29 & & 39 & 31 & \\
\hline OR $(95 \% \mathrm{CI})$ & 1.0 & $0.68(0.42-1.11)$ & 0.13 & 1.0 & $0.76(0.47-1.23)$ & 0.26 \\
\hline Adjusted $\mathrm{OR}^{\mathrm{a}}(95 \% \mathrm{CI})$ & 1.0 & $0.69(0.42-1.12)$ & 0.13 & 1.0 & $0.72(0.44-1.17)$ & 0.18 \\
\hline \multicolumn{7}{|l|}{ Laser coagulation therapy } \\
\hline Cases & 18 & 20 & & 22 & 16 & \\
\hline $\mathrm{HR}(95 \% \mathrm{CI})$ & 1.0 & $1.11(0.58-2.12)$ & 0.76 & 1.0 & $0.70(0.36-1.34)$ & 0.28 \\
\hline Adjusted $\mathrm{HR}^{\mathrm{a}}(95 \% \mathrm{CI})$ & 1.0 & $1.13(0.59-2.18)$ & 0.71 & 1.0 & $0.62(0.32-1.21)$ & 0.16 \\
\hline \multicolumn{7}{|c|}{ Arteriovenous crossing changes (nicking) } \\
\hline Cases & 53 & 33 & & 49 & 37 & \\
\hline OR $(95 \% \mathrm{CI})$ & 1.0 & $0.60(0.38-0.94)$ & 0.025 & 1.0 & $0.72(0.46-1.11)$ & 0.14 \\
\hline Adjusted $\mathrm{OR}^{\mathrm{a}}(95 \% \mathrm{CI})$ & 1.0 & $0.60(0.38-0.95)$ & 0.030 & 1.0 & $0.66(0.42-1.04)$ & 0.074 \\
\hline \multicolumn{7}{|l|}{ Microaneurysms } \\
\hline Cases & 176 & 163 & & 176 & 163 & \\
\hline OR $(95 \% \mathrm{CI})$ & 1.0 & $0.89(0.69-1.15)$ & 0.37 & 1.0 & $0.86(0.67-1.10)$ & 0.23 \\
\hline Adjusted $\mathrm{OR}^{\mathrm{a}}(95 \% \mathrm{CI})$ & 1.0 & $0.91(0.69-1.20)$ & 0.52 & 1.0 & $0.73(0.55-0.96)$ & 0.025 \\
\hline \multicolumn{7}{|l|}{ Retinal haemorrhages } \\
\hline Cases & 305 & 288 & & 300 & 293 & \\
\hline OR $(95 \% \mathrm{CI})$ & 1.0 & $0.89(0.71-1.12)$ & 0.31 & 1.0 & $0.89(0.72-1.13)$ & 0.35 \\
\hline Adjusted $\mathrm{OR}^{\mathrm{a}}(95 \% \mathrm{CI})$ & 1.0 & $0.91(0.71-1.17)$ & 0.46 & 1.0 & $0.78(0.61-1.01)$ & 0.055 \\
\hline \multicolumn{7}{|c|}{ Cotton wool spots (soft exudates) } \\
\hline Cases & 96 & 84 & & 86 & 94 & \\
\hline OR $(95 \% \mathrm{CI})$ & 1.0 & $0.84(0.61-1.16)$ & 0.29 & 1.0 & $1.07(0.78-1.47)$ & 0.67 \\
\hline Adjusted $\mathrm{OR}^{\mathrm{a}}(95 \% \mathrm{CI})$ & 1.0 & $0.86(0.62-1.20)$ & 0.38 & 1.0 & $0.98(0.70-1.36)$ & 0.88 \\
\hline \multicolumn{7}{|l|}{ Hard exudates } \\
\hline Cases & 81 & 92 & & 95 & 78 & \\
\hline OR $(95 \% \mathrm{CI})$ & 1.0 & $1.14(0.82-1.58)$ & 0.43 & 1.0 & $0.76(0.55-1.06)$ & 0.10 \\
\hline Adjusted $\mathrm{OR}^{\mathrm{a}}(95 \% \mathrm{CI})$ & 1.0 & $1.20(0.85-1.69)$ & 0.29 & 1.0 & $0.66(0.47-0.94)$ & 0.019 \\
\hline \multicolumn{7}{|l|}{ Macular oedema } \\
\hline Cases & 37 & 20 & & 33 & 24 & \\
\hline OR $(95 \% \mathrm{CI})$ & 1.0 & $0.50(0.29-0.88)$ & 0.016 & 1.0 & $0.69(0.40-1.18)$ & 0.17 \\
\hline Adjusted $\mathrm{OR}^{\mathrm{a}}(95 \% \mathrm{CI})$ & 1.0 & $0.50(0.28-0.89)$ & 0.018 & 1.0 & $0.59(0.34-1.03)$ & 0.065 \\
\hline \multicolumn{7}{|l|}{ Any retinal vascular lesion } \\
\hline Cases & 329 & 313 & & 318 & 324 & \\
\hline OR $(95 \% \mathrm{CI})$ & 1.0 & $0.90(0.72-1.12)$ & 0.34 & 1.0 & $0.97(0.78-1.22)$ & 0.81 \\
\hline Adjusted $\mathrm{OR}^{\mathrm{a}}(95 \% \mathrm{CI})$ & 1.0 & $0.92(0.72-1.17)$ & 0.48 & 1.0 & $0.87(0.68-1.12)$ & 0.28 \\
\hline
\end{tabular}

${ }^{a}$ Adjusted for presence of retinal haemorrhages at baseline 
nicking was also reduced after blood pressure-lowering treatment, but similar reductions were not apparent for other lesions. Arteriovenous nicking and macular oedema have both been associated with hypertension and endothelial dysfunction $[19,20]$, providing a possible mechanistic explanation for these findings. The occurrence of vascular changes also predicts progression of retinopathy [21]. We could not detect any risk reduction in laser coagulation therapy of blood pressure-lowering treatment, in keeping with the entire ADVANCE study [11]. These results are also consistent with observations among diabetic patients in the Heart Outcomes Prevention Evaluation (HOPE) study showing no significant reduction in laser coagulation therapy after ramipril treatment, but the studies may not be comparable as HOPE was conducted in the mid-1990s [22]. These findings contrast with the results of UKPDS, which showed a reduction of one-third in retinopathy, which mainly consisted of a reduction in laser coagulation therapy [9]. These inconsistencies may be attributable to the fact that laser coagulation therapy is an insensitive but specific marker of the progression of retinopathy, which is influenced by treatment practice or healthcare access. Furthermore, discrepancies between our findings and those of UKPDS could reflect the shorter duration of treatment and better levels of glycaemic, blood pressure and lipid control in ADVANCE, contributing to slower progression of retinopathy.

Intensive blood glucose-lowering treatment did not significantly affect the incidence and progression of retinopathy, although the presence of several retinal vascular lesions tended to be lower among the intensively treated group compared with the group receiving standard treatment. This is consistent with results in the first years of follow-up in UKPDS. After only 3 years of follow-up, UKPDS observed a relative risk of intensive vs conventional glucose control of 1.03 (99\% CI 0.79-1.34) for progression of $\geq 2$ steps in ETDRS classification. This relative risk was only $0.83(95 \%$ CI $0.67-1.01)$ after both 6 and 9 years of follow-up, while only after 12 years of follow-up was a borderline significant relative risk of 0.79 (0.63-1.00) observed [8]. For a combined endpoint of microvascular endpoints, the UKPDS recorded a $25 \%$ reduction in more than 10 years of follow-up, most of which was attributable to a reduction in cases of retinal photocoagulation [8]. In addition, the Veterans Affairs Diabetes Trial did not detect any reduction in the incidence or progression of retinopathy after intensive glucoselowering treatment [23]. Among type 1 diabetic patients, a similar risk reduction of retinopathy was found in the Diabetes Control and Complications Study over 6.5 years [24]. This risk reduction persisted for 4 years after termination of the trial [25]. Similarly, the UKPDS recently reported that, despite a loss of glycaemic differences, the reduced risk of microvascular disease continued and risk reductions for myocardial infarction and death emerged during 10 years of post-trial follow-up [26]. Altogether, these studies suggest that a longer period is needed for intensive glucose control to result in clinically relevant risk reductions in retinopathy. The presence of certain retinal vascular lesions, such as macular oedema and microaneurysms, tended to be reduced after intensive glucoselowering treatment. Since vascular changes predict the progression of retinopathy [21], these changes may herald reduced progression of retinopathy. However, longer follow-up is needed to establish this.

In conclusion, the AdRem Study could not demonstrate significant reductions in retinopathy either with blood pressure-lowering treatment or with intensive glucose control. Nevertheless, there were clear trends to reduction in the incidence and progression of retinopathy by $\geq 2$ steps in the ETDRS classification, for blood pressure lowering with the fixed combination of perindopril and indapamide, and for intensive glucose control with the gliclazide MRbased regimen, in type 2 diabetic patients. These trends were supported by the reduced incidence of retinal vascular lesions and were independent of initial blood pressures or $\mathrm{HbA}_{1 \mathrm{c}}$. A longer period of active treatment and larger numbers of patients are needed to demonstrate more definitive benefits.

Acknowledgements The ADVANCE and AdRem studies were funded by grants from Servier and the National Health and Medical Research Council of Australia. The sponsor of the study had no role in study design, data collection, data analysis, data interpretation or writing of the report. The corresponding author (J. W. J. Beulens) had full access to all data in the study. The Management Committee had final responsibility for the decision to submit for publication.

Duality of interest A. Patel has received lecture fees from Servier, Pfizer and Abbott and grant support from Pfizer, Servier and sanofi-aventis. D. E. Grobbee has received lecture fees from Servier and consulting and lecture fees and grant support from Pfizer, AstraZeneca, Novartis and sanofi-aventis.

\section{References}

1. Wild S, Roglic G, Green A, Sicree R, King H (2004) Global prevalence of diabetes: estimates for the year 2000 and projections for 2030. Diabetes Care 27:1047-1053

2. Klein BE (2007) Overview of epidemiologic studies of diabetic retinopathy. Ophthalmic Epidemiol 14:179-183

3. Younis N, Broadbent DM, Vora JP, Harding SP (2003) Incidence of sight-threatening retinopathy in patients with type 2 diabetes in the Liverpool Diabetic Eye Study: a cohort study. Lancet 361:195-200

4. Klein BE, Klein R, Moss SE, Palta M (1995) A cohort study of the relationship of diabetic retinopathy to blood pressure. Arch Ophthalmol 113:601-606

5. Klein R (1995) Hyperglycemia and microvascular and macrovascular disease in diabetes. Diabetes Care 18:258-268 
6. Stolk RP, Vingerling JR, de Jong PT et al (1995) Retinopathy, glucose, and insulin in an elderly population. The Rotterdam Study. Diabetes 44:11-15

7. Stratton IM, Kohner EM, Aldington SJ et al (2001) UKPDS 50: risk factors for incidence and progression of retinopathy in type II diabetes over 6 years from diagnosis. Diabetologia 44:156-163

8. UK Prospective Diabetes Study (UKPDS) Group (1998) Intensive blood-glucose control with sulphonylureas or insulin compared with conventional treatment and risk of complications in patients with type 2 diabetes (UKPDS 33). Lancet 352:837-853

9. UK Prospective Diabetes Study (UKPDS) Group (1998) Tight blood pressure control and risk of macrovascular and microvascular complications in type 2 diabetes: UKPDS 38. BMJ 317:703-713

10. Matthews DR, Stratton IM, Aldington SJ, Holman RR, Kohner EM (2004) Risks of progression of retinopathy and vision loss related to tight blood pressure control in type 2 diabetes mellitus: UKPDS 69. Arch Ophthalmol 122:1631-1640

11. Patel A, MacMahon S, Chalmers J et al (2007) Effects of a fixed combination of perindopril and indapamide on macrovascular and microvascular outcomes in patients with type 2 diabetes mellitus (the ADVANCE trial): a randomised controlled trial. Lancet 370:829-840

12. American Diabetes Association (2008) Standards of medical care in diabetes-2008. Diabetes Care 31(Suppl 1):S12-S54

13. Clemens A, Siegel E, Gallwitz B (2004) Global risk management in type 2 diabetes: blood glucose, blood pressure, and lipidsupdate on the background of the current guidelines. Exp Clin Endocrinol Diabetes 112:493-503

14. Patel A, MacMahon S, Chalmers J et al (2008) Intensive blood glucose control and vascular outcomes in patients with type 2 diabetes. N Engl J Med 358:2560-2572

15. Stolk RP, Vingerling JR, Cruickshank JK et al (2007) Rationale and design of the AdRem study: evaluating the effects of blood pressure lowering and intensive glucose control on vascular retinal disorders in patients with type 2 diabetes mellitus. Contemp Clin Trials 28:6-17

16. The ADVANCE Collaborative Group (2001) Rationale and design of the ADVANCE study: a randomised trial of blood pressure lowering and intensive glucose control in high-risk individuals with type 2 diabetes mellitus. Action in Diabetes and Vascular Disease: PreterAx and DiamicroN Modified-Release Controlled Evaluation. J Hypertens Suppl 19:S21-S28
17. Early Treatment Diabetic Retinopathy Study Research Group (1991) Grading diabetic retinopathy from stereoscopic color fundus photographs - an extension of the modified Airlie House classification. ETDRS report number 10. Ophthalmology 98:786806

18. Sjolie AK, Klein R, Porta M et al (2008) Effect of candesartan on progression and regression of retinopathy in type 2 diabetes (DIRECT-Protect 2): a randomised placebo-controlled trial. Lancet 372:1385-1393

19. Girach A, Lund-Andersen H (2007) Diabetic macular oedema: a clinical overview. Int J Clin Pract 61:88-97

20. Klein R, Sharrett AR, Klein BE et al (2000) Are retinal arteriolar abnormalities related to atherosclerosis?: The Atherosclerosis Risk in Communities Study. Arterioscler Thromb Vasc Biol 20:1644 1650

21. Klein R, Klein BE, Moss SE et al (2004) The relation of retinal vessel caliber to the incidence and progression of diabetic retinopathy: XIX: the Wisconsin Epidemiologic Study of Diabetic Retinopathy. Arch Ophthalmol 122:76-83

22. Heart Outcomes Prevention Evaluation Study Investigators (2000) Effects of ramipril on cardiovascular and microvascular outcomes in people with diabetes mellitus: results of the HOPE study and MICRO-HOPE substudy. Lancet 355:253-259

23. Duckworth W, Abraira C, Moritz T et al (2009) glucose control and vascular complications in veterans with type 2 diabetes. N Engl J Med 360:129-139

24. The Diabetes Control and Complications Trial Research Group (1993) The effect of intensive treatment of diabetes on the development and progression of long-term complications in insulin-dependent diabetes mellitus. N Engl J Med 329:977986

25. The Diabetes Control and Complications Trial/Epidemiology of Diabetes Interventions and Complications Research Group (2000) Retinopathy and nephropathy in patients with type 1 diabetes four years after a trial of intensive therapy. N Engl J Med 342:381-389

26. Holman RR, Paul SK, Bethel MA, Matthews DR, Neil HA (2008) 10-year follow-up of intensive glucose control in type 2 diabetes. N Engl J Med 359:1577-1589

27. Hubbard LD, Brothers RJ, King WN, Clegg LX, Klein R, Cooper LS, Sharrett AR, Davis MD, Cai J (1999) Methods for evaluation of retinal microvascular abnormalities associated with hypertension/sclerosis in the Atherosclerosis Risk in Communities Study. Ophthalmology; 106:2269-2280 